\title{
The Effect of Neuro-linguistic Programming Coaching on Learning English
}

\author{
Hayat Eid Alroudhan* \\ Department of English Language and Literature, College of Languages and Translation, Al-Imam Mohammad Ibn Saud Islamic \\ University, Saudi Arabia
}

Corresponding Author: Hayat Eid Alroudhan, E-mail: hayat.alroudhan@gmail.com

\begin{tabular}{l} 
ARTICLE INFO \\
\hline Article history \\
Received: February 07, 2018 \\
Accepted: April 19, 2018 \\
Published: July 01, 2018 \\
Volume: $7 \quad$ Issue: 4 \\
Advance access: May 2018 \\
\hline
\end{tabular}

Conflicts of interest: None

Funding: None

\begin{abstract}
NLP is an interpersonal communications model based on the belief that language is strongly inter-connected with neurological processes and behavioral patterns adopted through experience and the power of this connection can be harnessed to acquire the skills in exceptional people. The aim of the present study is to evaluate the efficiency of NLP for language learning and investigate its potential role in learning the English language. By using primary and secondary sources and implementing the Oxford Placement Test, as the pretest and the post-test on the experimental and control groups, the effect of the NLP coaching treatment sessions on the experimental group of female Saudi EFL learners was investigated for two months. The findings of this study reveal that NLP not only provides the techniques and solutions to the problems, but it also enables teachers to form their own flexible responses to the specific problems. In this study, NLP coaching proved to have a significant effect on EFL learning, however, further research is needed to confirm the findings of this innovative study.
\end{abstract}

Key words: Neuro-Linguistic Programming, English Language Learning, Coaching Effectiveness, Language Teachers, University Students

\section{INTRODUCTION}

\section{Background and Context}

Learning can occur in a variety of forms, depending on how we choose to look at this process and how it should be materialized. Over the years, a lot of learning approaches and techniques have emerged and increasingly found their place in academic circles. One of these approaches is Neuro-linguistic programming (NLP). Recently, there has been a surge in interest in NLP, which is believed to have a great potential for coaching and learning. A better understanding and knowledge of NLP, to improve language learning, will equally lead to an improvement in learning opportunities for both instructors and learners. The present research aims to investigate NLP in order to determine its effectiveness in English Language Learning.

\section{Research Problem}

Developed by Richard Bandler and John Grinder in the 1970s, NLP is basically an interpersonal communications model based on the belief that neurological processes (neuro), language (linguistic), and behavioural patterns adopted through experience (programming) are all strongly interconnected and the power of this connection can be harnessed to acquire the skills in exceptional people. The efficiency of using the concept of NLP as therapy or as a personal development program was investigated.

One of the NLP techniques used in coaching is Linking Criteria technique in which the coach first needs to find out what is personally important to students (known as Highly Valued Criteria) and then impart what s/he wants according to their own criteria. This is one of the many NLP techniques used in coaching and teaching. The basic common idea, however, is to model the language and behaviour in a way so as to make learning happen. In its essence, NLP coaching involves developing and moulding states, encouraging learning, and enhancing the internal representations of learners to direct them towards the desired outcome (Bandler \& Grinder, 2012). If applied successfully, NLP is a model that can help teachers develop a functional relationship with students and direct their motivation and efforts towards the desired outcome (Kong, 2012).

As the education sector is becoming more research driven, several psycho-pedagogical issues have been identified. In general, students have started to manifest an increasingly negative attitude towards schooling. In response to this phenomenon, teachers are expected to try to make the learning process as easy as possible by establishing an effective relationship between learners and teachers. NLP has largely become an indispensable component of the learning process to meet learner needs. 
In spite of the fact that learning the English language is becoming more convenient and accessible in the contemporary world, there are still a lot of problems that could potentially render this learning process ineffective. The dynamics of NLP in the classroom setting provides effective communication and can facilitate the process of learning. Such a learning environment is considered more motivating to learn English and to overcome the issues arising from the common practice of teaching, generally witnessed in any English Language class. A study of the relationship between NLP and English language teachers' success at a high school showed a significant correlation between NLP and the attributes of successful teachers (Pishghadam et al, 2011).

\section{Purpose of the Study}

Due to the increasing significance of using NLP for language teachers, this study aims to investigate the NLP coaching and its effect on successful language learning. The purpose of this study is to address and answer the following research questions:

- $\quad$ Based on the findings of previous studies, is NLP an efficient tool for language learning?

- What is the possible role of NLP in English language learning?

\section{LITERATURE REVIEW}

Some recent studies have focused on investigating the applicability of NLP for improving the efficiency of the language learning process. As a new tool for both language teachers and learners, NLP offers a number of techniques to address the above issue and provides a framework to facilitate language learning. At its core, NLP coaching involves motivating students to learn and for this, one needs to connect the value of learning with what is valuable to them (Kong \& Farrell, 2012).

\section{Trends in Neuro-Linguistic Programming}

The term "Neuro-Linguistic Programming" (NLP) refers to the approach to personal development, psychotherapy, and communication introduced by John Grinder, American linguist, management consultant, author, speaker, and trainer, and Richard Bandler, American trainer and author, in the 1970s (Bandler and Grinder, 2012). In order to understand the concept, and the practical use, of NLP better, we need to consider the three words in NLP, i.e. neurology, language, and programming, separately. They are probably the three most influential components in the production of human experience. According to Bandler and Grinder (2012), there is a profound relationship between these three components. These components can also be modified in order to achieve specific goals in life.

NLP is administered in order to assess the multi-dimensional process in humans that involves behavioral development in terms of flexibility and competence. It also involves understanding cognitive and mental processes that are believed to exist in human behavior. This can also be called strategic thinking in humans. According to Robert and Santa
(2016), NLP provides skills and tools needed to develop and promote individual excellence. In addition, it builds the system that empowers the presuppositions and beliefs concerning human nature as well as their communication systems in terms of changes. Kong (2012) argues that NLP is mainly used for self-discovery as well as exploring identity and mission. It also provides a framework to be used to understand and relate it to the spirituality of human experience, which permeates from individuals to families, communities, and global systems (Biswal and Prusty, 2011).

\section{NLP for Language Teachers}

According to Pishghadam and Shayesteh (2014), NLP is a supplementary tool used by language instructors to support language learning, particularly second language learning. In today's teaching and learning context, keeping language learners motivated is a difficult task for language instructors. Pishghadam and Shayesteh (2014) believe that "NLP is now emerging as an emotional bridge that helps teachers to build and maintain functional rapport with students and motivate them throughout their learning journey towards success" (p. 2096). On the other hand, NLP, as a new approach to language learning and teaching, offers many solutions for classroom-related issues and, thus, provides the resources that are essential to language teaching. In the context of learning English as a second language, Naeem (2011) cites three principles related to NLP that can be used to improve the writing and reading skills of learners:

- Learners must have a clear idea of their goals;

- Learners must be active regarding what they are gaining;

- Learners must be flexible and willing to change their behavior until they get what they want.

It is believed that the NLP begins with individuals' interest in how they do certain tasks. By using the NLP in teaching EFL (English as a foreign language), language teachers are informed about how students think and learn the language.

In NLP coaching, teachers can use their own personal experiences to conceptualize the language for learners, which makes it a very strong motivational tool. Teachers can also create artificial contexts to be used as the supporting material in the classroom (Pishghadam \& Shayesteh, 2014). The most remarkable aspect, however, is the way the NLP techniques enable teachers to form an association between what learners see and hear and their emotional state. These associations, called 'anchors', have proved to be very successful in memory recall and thus, using them in an English language class can yield the desired results (Lashkarian \& Sayadian, 2015). NLP techniques also help build and maintain a positive rapport with learners. Needless to say, a good rapport is at the core of every healthy learning experience. It also helps develop a sense of community in the classroom in which students actively engage in various tasks. Research has shown that students who are on good terms with their teachers are more motivated to learn and tend to have a better understanding of the material at hand (Bashir \& Ghani, 2012).

In their study, Sharif \& Aziz (2015) present an example of "Linking Criteria" technique in the NLP. The first step in 
this technique is to identify the highly-valued criteria of the students. Each student has different criteria so one cannot motivate every student in the same way. Usually, a person's criteria can be identified by finding out what already motivates that person. For instance, a student who plays video games may say that he plays them because, first, it is fun to compete against others and second, he loves being on top. Its logical conclusion could point to the student's emotional response underlying the fact that he wants to both have fun in the classroom and also function in a competitive learning environment. The next step is to link the criteria with the learning goals. This technique, if administered properly by the teacher in class, can make the process of language learning much more effective. There are other NLP techniques such as anchoring, creating rapport, and reframing that can be applied by both learners and educators in language classes to facilitate learning. These techniques can help educators communicate better with students, promote the learning environment, and result in a positive rapport that will, in its turn, lead to academic effectiveness (Sharif \& Aziz, 2015).

\section{Effect of NLP on the life of University Students}

NLP has a considerable impact on the life of university students in that it has the potential to enhance students' quality of life. It helps students develop positive perceptions and ideas about their quality of life and can provide support to students in resolving the issues they face in their current life. In addition, NLP also affects student life as it provides support to students in resolving psychological problems and influences the overall attitude of students positively (Turan, Kodaz \& Turan, 2016). It is a very useful tool for students as it helps them resolve their issues and problems and, at the same time, fosters personal growth and learning.

The life of university students is also affected by NLP as it has a significant influence on the family and personal life of students and can boost, and help achieve, individual fulfillment. Students use these techniques to develop positive interaction with others and ensure better communication with other people. Students can use NLP principles for enjoyment, making better decisions and life choices, and building a peaceful environment. NLP can be used by students to promote communication skills and boost the process of appearance, memory, and intelligence (Salami, 2015). NLP can also be used by students as a psychotherapeutic technique to bring excitement, happiness, joy, and success to students.

\section{Role of NLP in Classroom}

NLP has a significant role in providing classroom instruction to students. It is an approach that has great potential for being extensively used in EFL classroom settings, as it can be used to achieve excellent learner performance. NLP can also be integrated for classroom instruction. It can be used to discuss new ideas and grammar points, e.g. ideas can be written on board and gestures and speaking aloud can be used to deliver them (Richards, \& Rodgers, 2014). This approach is also useful in the application of improvements in English instruction. In the classroom, this program provides an opportunity to all students to achieve potential learning in the environment (Ilyas, 2017). NLP, as an approach for presenting instructions in the classroom, ensures that no student is left behind in the process of learning and understanding. It ensures equal learning opportunities for all students and enables teachers to make a curriculum that is easy to learn (Burstein et al. 2014). It also guarantees the provision of basic learning and understanding to students in the classroom by enhancing students' communication skills and ensuring true equality in the learning process and environment. To eliminate stress in students, NLP techniques should be implemented daily, as NLP in the classroom setting plays an important role in the improvement of students' communication skills, learning, and achievement of success.

\section{METHODOLOGY}

\section{Research Methodology}

The present study uses both primary and secondary research. At first, the hypothesis and conceptual framework of the research is developed in light of previous scholarly research. To ensure the validity of the findings, only peer-reviewed journal articles and conference papers are included in the review.

\section{Tool}

The primary research is conducted by applying Oxford Placement Test, as a pretest and post-test to the experimental and control groups. Language students with and without the experience of using NLP for learning English are targeted for the primary research. The test helps to identify the influence of the NLP coaching treatment sessions on the experimental group for two months.

\section{Participants}

The sample consists of six classes from the first grade of the second stage students (ages 15 to 16) in 47 public schools for girls in Riyadh in Saudi Arabia. Three classes comprised the experimental group and the other three were the control group. 'Simple random sampling' method was used for selecting the participants for the primary research so as to avoid bias in the participants' responses. The statistical methods of regression and correlation coefficient analysis were used to reach the findings of the study.

\section{DATA ANALYSES AND FINDINGS}

\section{Reliability}

Cronbach's Alpha coefficient test is used to verify the consistency of responses for words in both of the two dialects. Cronbach's Alpha for coefficient values for the experimental and control groups are 0.639 and 0.839 , respectively. These values are statistically accepted since they are higher than the statically permitted rate of $60 \%$. Table 1 shows the reliability of the study variables for the experimental and control groups, as follows:

After applying Cronbach's Alpha with satisfactory results for both groups (the experimental and control groups), the researcher measured the frequencies, the means, and the standard 
deviations. In the next step, the researcher applied a paired t-test to resolve the statistical differences in the answers of the two groups, the accepted significance level being $0.05(\alpha=0.05)$.

\section{Data Analysis}

This study aims at answering the two research questions that try to determine the role of NLP in English language learning in an experimental and a control group. We conducted this test on the sample of study, in 25 parts, and the results are displayed in the following Tables.

Q: What is the possible role of NLP in English language learning?

\section{Descriptive Analysis of Students' Grades}

Table 2 shows the recorded grades for the control group in the pre and post test stages, as follows:

Table 1. Cronbach's alpha coefficients

\begin{tabular}{ll}
\hline Cronbach's alpha & The groups \\
\hline 0.474 & Experimental group \\
0.1 & Control group \\
0.025 & Both groups \\
\hline
\end{tabular}

Table 2. The pre \& post Test results of the control group

\begin{tabular}{|c|c|c|c|c|c|}
\hline \multicolumn{3}{|c|}{ Post test } & \multicolumn{3}{|c|}{ Pre test } \\
\hline$\%$ & Frequency & The grade & $\%$ & Frequency & The grade \\
\hline 1.8 & 1 & 23 & 3.6 & 2 & 4 \\
\hline 1.8 & 1 & 25 & 1.8 & 1 & 7 \\
\hline 3.6 & 2 & 26 & 1.8 & 1 & 16 \\
\hline 3.6 & 2 & 28 & 1.8 & 1 & 19 \\
\hline 5.4 & 3 & 29 & 1.8 & 1 & 25 \\
\hline 12.5 & 7 & 30 & 3.6 & 2 & 26 \\
\hline 5.4 & 3 & 31 & 5.4 & 3 & 27 \\
\hline 8.9 & 5 & 32 & 3.6 & 2 & 28 \\
\hline 14.3 & 8 & 33 & 8.9 & 5 & 29 \\
\hline 5.4 & 3 & 34 & 7.1 & 4 & 30 \\
\hline 8.9 & 5 & 35 & 3.6 & 2 & 31 \\
\hline 5.4 & 3 & 36 & 5.4 & 3 & 32 \\
\hline 8.9 & 5 & 37 & 7.1 & 4 & 33 \\
\hline 1.8 & 1 & 38 & 8.9 & 5 & 34 \\
\hline 3.6 & 2 & 39 & 3.6 & 2 & 35 \\
\hline 3.6 & 2 & 40 & 12.5 & 7 & 36 \\
\hline 3.6 & 2 & 42 & 5.4 & 3 & 37 \\
\hline \multirow[t]{6}{*}{1.8} & 1 & 43 & 3.6 & 2 & 38 \\
\hline & & & 1.8 & 1 & 39 \\
\hline & & & 1.8 & 1 & 41 \\
\hline & & & 1.8 & 1 & 42 \\
\hline & & & 1.8 & 1 & 44 \\
\hline & & & 3.6 & 2 & 45 \\
\hline 100 & 56 & Total & 100 & 56 & Total \\
\hline
\end{tabular}

Table 2 shows that the most frequent grade of the pretest stage is 36 , with $12.5 \%$ of the total grades. The two lowest grades at this stage are each 4 and $7.9 \%$ of the grades are higher than $40.58 .9 \%$ of the grades are between 30 and 40 and $67.8 \%$ are higher than 30 . In the post-test stage, the most frequent grade is 33 and there is no grade less than $20.83 .9 \%$ of the grades are higher than 30 .

Table 3 shows that the most frequent grades in the pretest stage are 26, 29, 30 and 33, altogether comprising $31.6 \%$ of the total grades. There are no grades less than 10 at this stage, but there are three grades less than $20.66 .7 \%$ of the grades are between 30 and 45 and $7.9 \%$ are higher than 40 .

The most frequent grade of the post-test stage is 37 which comprises $14.3 \%$ of the total grades. There is one grade less than 10 at this stage (i.e., grade 9 ) and $68.8 \%$ of the grades are between 30 and 45 .

Table 4 is a comparison between the pretest results of the control and experimental groups. The most frequent grade of the pre-test stage is 36 , with $12.5 \%$ percent of the total grades. The two lowest grades at this stage are 4 and 7 and $9 \%$ of the grades are higher than 40 . Also, $58.9 \%$ of the grades are between 30 and 40 and $67.8 \%$ are higher than 30 .

Table 3. The pre \& post test results of the experimental group

\begin{tabular}{|c|c|c|c|c|c|}
\hline \multirow{2}{*}{$\begin{array}{l}\text { The } \\
\text { grade }\end{array}$} & \multicolumn{2}{|c|}{ Pre test } & \multirow{2}{*}{$\begin{array}{c}\text { The } \\
\text { grade }\end{array}$} & \multicolumn{2}{|c|}{ Post test } \\
\hline & Frequency & $\%$ & & Frequency & $\%$ \\
\hline 16.00 & 1 & 1.6 & 9.00 & 1 & 1.6 \\
\hline 17.00 & 1 & 1.6 & 22.00 & 2 & 3.2 \\
\hline 18.00 & 1 & 1.6 & 25.00 & 1 & 1.6 \\
\hline 20.00 & 1 & 1.6 & 26.00 & 2 & 3.2 \\
\hline 21.00 & 1 & 1.6 & 27.00 & 2 & 3.2 \\
\hline 24.00 & 2 & 3.2 & 28.00 & 2 & 3.2 \\
\hline 25.00 & 1 & 1.6 & 29.00 & 3 & 4.8 \\
\hline 26.00 & 5 & 7.9 & 31.00 & 6 & 9.5 \\
\hline 27.00 & 2 & 3.2 & 32.00 & 4 & 6.3 \\
\hline 28.00 & 1 & 1.6 & 33.00 & 6 & 9.5 \\
\hline 29.00 & 5 & 7.9 & 34.00 & 4 & 6.3 \\
\hline 30.00 & 5 & 7.9 & 35.00 & 8 & 12.7 \\
\hline 31.00 & 4 & 6.3 & 36.00 & 2 & 3.2 \\
\hline 32.00 & 2 & 3.2 & 37.00 & 9 & 14.3 \\
\hline 33.00 & 5 & 7.9 & 38.00 & 7 & 11.1 \\
\hline 34.00 & 3 & 4.8 & 39.00 & 1 & 1.6 \\
\hline 35.00 & 3 & 4.8 & 40.00 & 1 & 1.6 \\
\hline 36.00 & 3 & 4.8 & 41.00 & 2 & 3.2 \\
\hline 37.00 & 4 & 6.3 & & & \\
\hline 38.00 & 4 & 6.3 & & & \\
\hline 39.00 & 2 & 3.2 & & & \\
\hline 40.00 & 2 & 3.2 & & & \\
\hline 41.00 & 1 & 1.6 & & & \\
\hline 43.00 & 3 & 4.8 & & & \\
\hline 45.00 & 1 & 1.6 & & & \\
\hline Total & 63 & 100.0 & Total & 63 & 100 \\
\hline
\end{tabular}


The most frequent grades of the pre-test stage are 26, 29, 30 and 33, altogether making up $31.6 \%$ of the total grades. There are no grades less than 10 at this stage, but there are three grades less than $20.66 .7 \%$ of the grades are between 30 and 45 and $7.9 \%$ of the grades are higher than 40 .

Table 5 shows the post-test results of the control and experimental groups. The most frequent grade of the posttest stage is 33 . There are no grades less than 20 at this stage and $83.9 \%$ of the grades are higher than 30 . The most frequent grade of the post-test stage is 37 , with $14.3 \%$ of the total grades. At this stage, there is one grade less than 10 , i.e., grade 9 , and $68.8 \%$ of the grades are between 30 and 45 .

Mean and Standard Deviation of Control and Experimental Groups
A. The Pre Test Stage
B. The Post Test Stage

Table 6 shows the mean grades of students in the control group at 31.32 , which is less than the mean grades of students in the experimental group, at 31.95 .

Table 4. The pre test results of the control and experimental groups

\begin{tabular}{|c|c|c|c|c|c|}
\hline \multicolumn{3}{|c|}{ Control group } & \multicolumn{3}{|c|}{ Experimental group } \\
\hline $\begin{array}{l}\text { The } \\
\text { grade }\end{array}$ & Frequency & $\%$ & $\begin{array}{l}\text { The } \\
\text { grade }\end{array}$ & Frequency & $\%$ \\
\hline 4.00 & 2 & 3.6 & 16.00 & 1 & 1.6 \\
\hline 7.00 & 1 & 1.8 & 17.00 & 1 & 1.6 \\
\hline 16.00 & 1 & 1.8 & 18.00 & 1 & 1.6 \\
\hline 19.00 & 1 & 1.8 & 20.00 & 1 & 1.6 \\
\hline 25.00 & 1 & 1.8 & 21.00 & 1 & 1.6 \\
\hline 26.00 & 2 & 3.6 & 24.00 & 2 & 3.2 \\
\hline 27.00 & 3 & 5.4 & 25.00 & 1 & 1.6 \\
\hline 28.00 & 2 & 3.6 & 26.00 & 5 & 7.9 \\
\hline 29.00 & 5 & 8.9 & 27.00 & 2 & 3.2 \\
\hline 30.00 & 4 & 7.1 & 28.00 & 1 & 1.6 \\
\hline 31.00 & 2 & 3.6 & 29.00 & 5 & 7.9 \\
\hline 32.00 & 3 & 5.4 & 30.00 & 5 & 7.9 \\
\hline 33.00 & 4 & 7.1 & 31.00 & 4 & 6.3 \\
\hline 34.00 & 5 & 8.9 & 32.00 & 2 & 3.2 \\
\hline 35.00 & 2 & 3.6 & 33.00 & 5 & 7.9 \\
\hline 36.00 & 7 & 12.5 & 34.00 & 3 & 4.8 \\
\hline 37.00 & 3 & 5.4 & 35.00 & 3 & 4.8 \\
\hline 38.00 & 2 & 3.6 & 36.00 & 3 & 4.8 \\
\hline 39.00 & 1 & 1.8 & 37.00 & 4 & 6.3 \\
\hline 41.00 & 1 & 1.8 & 38.00 & 4 & 6.3 \\
\hline 42.00 & 1 & 1.8 & 39.00 & 2 & 3.2 \\
\hline 44.00 & 1 & 1.8 & 40.00 & 2 & 3.2 \\
\hline \multirow[t]{2}{*}{45.00} & 2 & 3.6 & 41.00 & 1 & 1.6 \\
\hline & & & 43.00 & 3 & 4.8 \\
\hline \multirow[t]{3}{*}{ Total } & & 100 & 45.00 & 1 & 1.6 \\
\hline & 56 & & & & \\
\hline & & & Total & 63 & 100.0 \\
\hline
\end{tabular}

Table 7 shows the mean grades of students in the control group at 33.268, which is higher than the mean grades of students in the experimental group, at 33.12.

The conclusion that could be drawn is that there is an improvement in the grades of the control group with regard to the concept of 'NLP for English language learning' conducted by the researcher in this study (the post-test). At the same time, differences between the control group and the experimental group were documented.

Descriptive statistics of pre and post tests for the three classes of the control group

\begin{tabular}{lcccccc}
\hline & \multirow{2}{*}{$\mathbf{N}$} & \multicolumn{2}{c}{ Pre test } & & \multicolumn{2}{c}{ Post test } \\
\cline { 3 - 4 } \cline { 6 - 6 } & & Mean & S.D & & Mean & S.D \\
\hline CLASS1 & 17 & 33.2353 & 6.42777 & & 34.7059 & 4.92144 \\
CLASS2 & 25 & 29.9600 & 11.08858 & & 33.4000 & 4.05175 \\
CLASS3 & 14 & 31.4286 & 3.67349 & & 31.2857 & 3.40652 \\
Valid N & 14 & & & & \\
(listwise) & & & & & \\
\hline
\end{tabular}

Descriptive statistics of pre and post tests for the three classes of the experimental group

\begin{tabular}{lccccc}
\hline & N & \multicolumn{2}{c}{ Pre test } & \multicolumn{2}{c}{ Post test } \\
\cline { 3 - 6 } & & Mean & S.D & Mean & S.D \\
\hline CLASS1 & 25 & 30.8800 & 5.05239 & 33.6000 & 4.31084 \\
CLASS2 & 16 & 32.2500 & 7.46101 & 33.0625 & 4.75351
\end{tabular}

Table 5. The Post test results of the control and experimental groups

\begin{tabular}{|c|c|c|c|c|c|}
\hline \multicolumn{3}{|c|}{ Control group } & \multicolumn{3}{|c|}{ Experimental group } \\
\hline $\begin{array}{l}\text { The } \\
\text { grade }\end{array}$ & Frequency & $\%$ & $\begin{array}{c}\text { The } \\
\text { grade }\end{array}$ & Frequency & $\%$ \\
\hline 23.00 & 1 & 1.8 & 9.00 & 1 & 1.6 \\
\hline 25.00 & 1 & 1.8 & 22.00 & 2 & 3.2 \\
\hline 26.00 & 2 & 3.6 & 25.00 & 1 & 1.6 \\
\hline 28.00 & 2 & 3.6 & 26.00 & 2 & 3.2 \\
\hline 29.00 & 3 & 5.4 & 27.00 & 2 & 3.2 \\
\hline 30.00 & 7 & 12.5 & 28.00 & 2 & 3.2 \\
\hline 31.00 & 3 & 5.4 & 29.00 & 3 & 4.8 \\
\hline 32.00 & 5 & 8.9 & 31.00 & 6 & 9.5 \\
\hline 33.00 & 8 & 14.3 & 32.00 & 4 & 6.3 \\
\hline 34.00 & 3 & 5.4 & 33.00 & 6 & 9.5 \\
\hline 35.00 & 5 & 8.9 & 34.00 & 4 & 6.3 \\
\hline 36.00 & 3 & 5.4 & 35.00 & 8 & 12.7 \\
\hline 37.00 & 5 & 8.9 & 36.00 & 2 & 3.2 \\
\hline 38.00 & 1 & 1.8 & 37.00 & 9 & 14.3 \\
\hline 39.00 & 2 & 3.6 & 38.00 & 7 & 11.1 \\
\hline 40.00 & 2 & 3.6 & 39.00 & 1 & 1.6 \\
\hline 42.00 & 2 & 3.6 & 40.00 & 1 & 1.6 \\
\hline 43.00 & 1 & 1.8 & 41.00 & 2 & 3.2 \\
\hline Total & 56 & 100 & Total & 63 & 100 \\
\hline
\end{tabular}


Table 6. Pre test descriptive statistics

\begin{tabular}{lccccc}
\hline & N & Minimum & Maximum & Mean & Standard deviation \\
\hline Control & 56 & 4.00 & 45.00 & 31.3214 & 8.41667 \\
Experimental & 63 & 16.00 & 45.00 & 31.9524 & 6.48678 \\
\hline
\end{tabular}

Table 7. Post test descriptive statistics

\begin{tabular}{lccccc}
\hline & N & Minimum & Maximum & Mean & Standard deviation \\
\hline Control & 56 & 23.00 & 43.00 & 33.2679 & 4.31273 \\
Experimental & 63 & 9.00 & 41.00 & 33.1270 & 5.33247 \\
\hline
\end{tabular}

\begin{tabular}{llllll} 
CLASS3 & 22 & 32.9545 & 7.26687 & 32.6364 & 6.78616 \\
Valid & 16 & & & & \\
N (listwise) & & & & & \\
\hline
\end{tabular}

\section{Descriptive statistics of the pre-test for the three} classes of control and experimental groups

\begin{tabular}{lcccc}
\hline & \multicolumn{2}{c}{ Control group } & \multicolumn{2}{c}{ Experimental group } \\
\cline { 2 - 5 } & Mean & S.D & Mean & S.D \\
\hline CLASS1 & 33.2353 & 6.42777 & 30.8800 & 5.05239 \\
CLASS2 & 29.9600 & 11.08858 & 32.2500 & 7.46101 \\
CLASS3 & 31.4286 & 3.67349 & 32.9545 & 7.26687 \\
Valid N & & & & \\
(listwise) & & & & \\
\hline
\end{tabular}

Descriptive statistics of the post-test for the three classes of control and experimental groups

\begin{tabular}{lccccc}
\hline & \multicolumn{2}{c}{ Control group } & & \multicolumn{2}{c}{$\begin{array}{c}\text { Experimental } \\
\text { group }\end{array}$} \\
\cline { 2 - 3 } \cline { 6 - 6 } & Mean & S.D & & Mean & S.D \\
\hline CLASS1 & 34.7059 & 4.92144 & & 33.6000 & 4.31084 \\
CLASS2 & 33.4000 & 4.05175 & 33.0625 & 4.75351 \\
CLASS3 & 31.2857 & 3.40652 & 32.6364 & 6.78616 \\
Valid N (listwise) & & & & \\
\hline
\end{tabular}

\section{TESTING THE HYPOTHESIS}

We used the paired t-test to test the following hypothesis:

H0: There are statistically significant differences between the experimental and control groups in regard to NLP for English language learning.

Ha: There are no statistically significant differences between the experimental and control groups in regard to NLP for English language learning.
We used the paired t-test to test these hypotheses and to resolve the differences between the control and experimental groups. Table 9 shows the results.

The results show that the significance level of the paired t-test is 0.764 , which is higher than 0.05 (the statistically accepted level). It means we can accept the alternative hypothesis $\mathrm{Ha}$ (reject $\mathrm{H} 0$ ) which says, 'there are no statistically significant differences between the experimental and control groups in regard to NLP for English language learning'.

\section{DISCUSSION}

Based on the results of experimental and control groups in regard to NLP for English language learning, it can be stated that similar results were obtained. That is, the efficacy of the concept of NLP as therapy and/or as a personal development program was confirmed. For Bandler and Grinder (2012), "Linking Criteria" is one of the NLP techniques used in coaching in which the coach should first find out what is personally important to students (called the Highly Valued Criteria) and then connect what s/he wants to impart with their criteria. The results of this factor, investigated against the first hypothesis, were revealed as the same as found in the reviewed literature. For instance, the findings of the first hypothesis show that there are no statistically significant differences between the experimental and control groups in regard to NLP for English language learning.

On the other hand, it can be concluded that there is an improvement in the grades of the control group with regard to the concept of 'NLP for English language learning' conducted by the researcher in this study (the post-test). There are, of course, differences between the control group and the experimental group. Previous research has demonstrated that using NLP can increase the motivation level and make the

\begin{tabular}{|c|c|c|c|c|c|c|c|c|}
\hline \multicolumn{9}{|c|}{ Paired differences } \\
\hline & \multirow[t]{2}{*}{ Mean } & \multirow[t]{2}{*}{$\begin{array}{l}\text { Standard } \\
\text { deviation }\end{array}$} & \multirow[t]{2}{*}{$\begin{array}{c}\text { Standard error } \\
\text { mean }\end{array}$} & \multicolumn{2}{|c|}{$\begin{array}{l}95 \% \text { confidence } \\
\text { interval of the } \\
\text { difference }\end{array}$} & \multirow[t]{2}{*}{$\mathbf{t}$} & \multirow[t]{2}{*}{ df } & \multirow[t]{2}{*}{ Sig. (2-tailed) } \\
\hline & & & & Lower & Upper & & & \\
\hline \multicolumn{9}{|l|}{ Pair 1} \\
\hline Experiment & - & 7.97064 & 1.06512 & -2.45598 & 1.81312 & - & 55 & 0.764 \\
\hline Control & -0.32143 & & & & & $0.302-$ & & \\
\hline
\end{tabular}


classroom less demanding for teachers. The findings of this study also confirm the benefits of the application of the NLP.

\section{CONCLUSION}

This paper is a study of the topic of the incorporation of NLP in the practice of teaching English. This topic was selected due to the researcher's belief that this technique can make a noticeable change in students' learning experience. Previous research has shown that using NLP can increase students' motivation level and, at the same time, make classes less demanding for teachers. NLP provides techniques and solutions to problems and enables teachers to form their own flexible responses to specific problems.

However, the findings do not point to any perceptible progress in the experimental group, probably due to the age of subjects. In addition, the fact that the NLP teacher was not the English teacher of the class might have affected the results. For more effective results, it is recommended to integrate the NLP technique with English teaching classes. To the best of the researcher's knowledge, no similar study has been conducted in the past and thus the contribution would be significant. Analyzing the role of NLP in teaching English would contribute to an improvement in the efficiency of both instructors and learners.

\section{REFERENCES}

Bandler, R., and Grinder, J., (2012). Frogs into Princes: Neuro-Linguistic Programming. Real People Press.

Bashir, A., \& Ghani, M. (2012). Effective Communication and Neuro-linguistic Programming. Pakistan Journal of Commerce and Social Sciences, 6(1), 216-222.

Biswal, R., and Prusty, B. (2011). Trends in neuro-linguistic programming (NLP): A critical review. Social Science International, 27(1), p.41.

Burstein, J., Shore, J., Sabatini, J., Moulder, B., Lentini, J., Biggers, K., \& Holtzman, S. (2014). From Teacher Professional Development to the Classroom: How NLP Technology Can Enhance Teachers' Linguistic Awareness to Support Curriculum Development for English Language Learners. Journal of Educational Computing Research, 51(1), 119- 144.

Ilyas, M. (2017). Finding Relationships between Acquisition of Basic Skills and Neuro-linguistic Programming Techniques. constructions, 34 .

Kong, E. (2012). The potential of neuro-linguistic programming in human capital development. Electronic Journal of Knowledge Management, 10(2), 131-141.
Kong, E., \& Farrell, M. (2012). Facilitating knowledge and learning capabilities through neuro-linguistic programming. International Journal of Learning, 18(3).

Kong, E. (2012). The potential of neuro-linguistic programming in human capital development. Electronic Journal of Knowledge Management, 10 (2), pp.131-141.

Lashkarian, A., \& Sayadian, S. (2015). The Effect of Neuro-Linguistic Programming (NLP) Techniques on Young Iranian EFL Learners' Motivation, Learning Improvement, and on Teacher's Success. Procedia-Social and Behavioral Sciences, 199, 510-516

Naeem, P. (2011). NLP and English Language Teaching. [online] Neoenglishsystem.blogspot.com. Available at: http://neoenglishsystem.blogspot.com/2011/02/nlpand-english-language-teaching.html [Accessed 1 Aug. 2017].

Pishghadam, R. and Shayesteh, S., 2014. Neuro-linguistic programming (NLP) for language

teachers: revalidation of an NLP scale. Theory and Practice in Language Studies, 4(10), p.2096.

Pishghadam, R., \&Shayesteh, S. (2014). Neuro-linguistic programming (NLP) for language teachers: revalidation of an NLP scale. Theory and Practice in Language Studies, 4(10), 2096.

Pishghadam, R., Shayesteh, S., \&Shapoori, M. (2011). Validation of an NLP scale and its relationship with teacher success in high schools. Journal of language teaching and research, 2(4), 909-917.

Richards, J. C., \& Rodgers, T. S. (2014). Approaches and methods in language teaching. Cambridge university press.

Robert, B. and Santa, C. (2016). What Is NLP? . [online] Nlpu.com. Available at: http://www.nlpu.com/NLPU_ WhatIsNLP.html [Accessed 1 Aug. 2017].

Salami, S. (2015). IMPLEMENTING NEURO-LINGUISTIC PROGRAMMING (NLP) IN CHANGING STUDENTS'BEHAVIOR: RESEARCH DONE AT ISLAM$\mathrm{IC}$

UNIVERSITIES IN ACEH. Jurnal Ilmiah Peuradeun, 3(2), 235-256.

Sharif, S. \& Aziz, E. R. A. (2015). Application of neuro-linguistic programming techniques to enhance the motivation of at-risk students. IJAEDU-International E-Journal of Advances in Education, 1(1), 42-48.

Tosey, P., and Mathison, J. (2003). Neuro-linguistic programming and learning theory: A response. The Curriculum Journal, 14(3), pp.371-388.

Turan, H., Kodaz, K., \& Turan, G. (2016). The Effect of NLP Education on the Teaching Profession in Turkey. 